\title{
Im Hier und Jetzt leben - eine Lebenskunst?
}

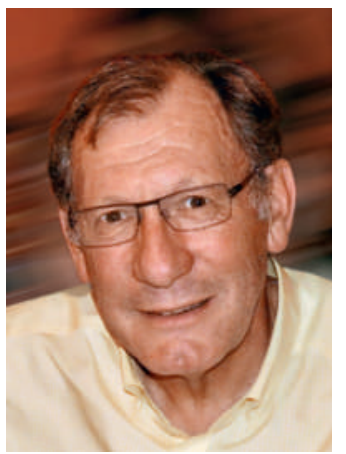

Jean Martin
Jon Kabat-Zinn hat lange an der University of Massachussetts Medical School gelehrt und einen grossen Beitrag dazu geleistet, dass dem Thema Stress im Alltag der ihm zukommende Stellenwert beigemessen wird. Ausserdem hat er sich in der Stressprävention engagiert und Programme mit einer wichtigen Meditationskomponente für Medizinstudenten, Mitarbeitende im Gesundheitswesen und andere entwickelt. Im Ruhestand, also in einem Lebensabschnitt, in dem jeder auf die eine oder andere Art darüber reflektiert, was war, was ist und was noch sein wird - habe ich sein Buch «Im Alltag Ruhe finden» [1], wieder einmal gelesen.

Kabat-Zinn spricht über die Bedeutung des Innehaltens, darüber, der rastlosen Aktivität, die viele von uns praktizieren, Einhalt zu gebieten. «Das Jetzt beobachten, ohne etwas daran ändern zu wollen. Beim Innehalten vollständig im Hier und Jetzt präsent sein.» «Es ist ein bisschen, als ob man stirbt, während das Leben weitergeht. Alle Verantwortung löst sich einfach in Luft auf. Was bleibt, wird ohne uns geregelt. Niemand kann unsere persönliche Agenda fortsetzen.» Ein Gedanke, der beunruhigen kann ... Ich persönlich finde ihn beruhigend.

Kabat-Zinn nimmt mehrmals Bezug auf den Amerikaner H. D. Thoreau und dessen Buch «Walden», das in zwei Jahren Einsamkeit am Ufer eines kleines Sees entstanden ist (1845-1847): «Ich zog in den Wald, weil ich den Wunsch hatte, mich den eigentlichen Tatsachen des Lebens zu stellen, weil ich versuchen wollte, etwas zu lernen, anstatt am Ende des Lebens zu erkennen, dass ich nicht wirklich gelebt hatte. [...] Die Vorstellung von der Ewigkeit ist wirklich erhaben. Aber all diese Momente, Orte und Gelegenheiten sind hier und jetzt.»

Kabat-Zinn: «Man muss nirgendwo hingehen, sondern sich erlauben, da zu sein, wo man ist.» Eine praktische Übung, um im Hier und Jetzt zu leben (Achtsamkeit zu lernen), besteht darin, dass wir die anderen beobachten und uns dabei fragen, ob wir wirklich sie sehen oder nur unser Urteil über sie.

Häufig - so Kabat-Zinn weiter - will ich mehr in den jeweiligen Moment hineinpacken. «Noch ein Telefongespräch, noch schnell etwas erledigen ... Ich arbeite hart daran, diesem Impuls nicht zu folgen. Er lenkt mich ab von dem, was mich umgibt. Ich kann mein Leben dann nicht vereinfachen. Jeweils nur eine Sache tun. Weniger sehen, um besser zu sehen, weniger tun, um mehr zu tun, weniger haben wollen, um mehr zu haben.»

Hierbei geht es um einen echten Paradigmenwechsel! All dies mag gut und schön sein, werden die
Kolleginnen und Kollegen im Notdienst und in der Pflege sagen. Aber wir sind nicht hier, um zu träumen. Oft ist es einfach nicht möglich, innezuhalten, um jeden Moment «bewusst erfahren» zu können.

Ich war immer in Eile, rannte von einer Aufgabe zur anderen, geizte mit meiner Zeit. Trotz meiner Pensionierung hat sich daran kaum etwas geändert. Kabat-Zinn spricht von «diesen vollen Terminkalendern, die uns beruhigen». Und dabei fällt mir wieder ein, dass er an einer grossen Universität lehrt, mit all dem, was dies an Aufgaben und Pflichten beinhaltet. Es ist gar nicht so leicht, diese Aktivität aufzugeben: «Für mich als Familienvater, der stark in seine Arbeit eingebunden ist, stellt die Vorstellung, mich jetzt einfach unter einen Baum zu setzen und das Gras wachsen zu hören, ein ernsthaftes Problem dar. Es gibt jedoch immer Mittel und Wege, sich für das Einfache zu entscheiden. [...] Vielleicht bereits die Entdeckung, dass weniger mehr sein kann.»

An dieser Stelle sei auf die Aussage erfolgreicher (männlicher oder weiblicher) Unternehmensleiter verwiesen, die betonen, dass sie effizienter sind, wenn sie sich die Zeit nehmen, innezuhalten und in irgendeiner Form $\mathrm{zu}$ meditieren. Ich hatte schon immer meine Probleme damit, solchen Aussagen zu vertrauen, aber warum sollten die Betroffenen nicht die Wahrheit sagen? Zweifellos ist die Suche nach der vollen Bewusstheit im Hier und Jetzt (mindfulness), ohne dabei allzu viel auf die Vergangenheit zu schauen und sich zu viele Gedanken um eine nahe oder ferne Zukunft zu machen, ein guter Weg.

Als leidenschaftlicher Entdecker ferner Welten berührt mich der von Kabat zitierte Satz von Lao-Tse: «Erkenne die Wege unter diesem Himmel, ohne die Schwelle deiner Tür zu überschreiten. Je weiter du dich entfernst, desto weniger erfährst du!» Abschliessend könnten wir uns jenen Wissenschaftlern nähern, die da sagen, dass sie, je tiefer sie in eine Materie eindringen, umso mehr sehen, wie gross unsere Unwissenheit ist.

Und zum Schluss: Walt Whitman, amerikanischer Dichter und Denker des 19. Jahrhunderts: «Es genügt mir, so zu existieren, wie ich bin. [...] Gleichgültig, ob sich meine Bestimmung heute oder in zehntausend Jahren erfüllt, ich kann sie jetzt freudig annehmen oder ebenso freudig warten.» Dazu nochmals Lao-Tse: «Hast du die Geduld zu warten, bis sich der Schlamm gesetzt hat und das Wasser wieder klar wird?»

Jean Martin, Mitglied der Redaktion 